\title{
PENGARUH TINGKAT KONSENTRASI FRAKSI EKSTRAK DAUN MENGKUDU DAN MIMBA TERHADAP PERTUMBUHAN DAN SPORULASI Colletotrichum capsici
}

\author{
Septy Anggreini, Efri \& Muhammad Nurdin \\ Jurusan Agroteknologi, Universitas Lampung \\ Jl. Prof. Dr. Soemantri Brodjonegoro, No 1, Bandar lampung 35145 \\ E-mail: septyanggreini8@gmail.com
}

\begin{abstract}
ABSTRAK
Salah satu penyakit utama yang menyerang tanaman cabai adalah penyakit antraknosa yang disebabkan oleh Colletotrichum capsici. Penelitian ini bertujuan untuk mengetahui tingkat keefektifan fraksi ekstrak daun mengkudu dan fraksi ekstrak daun mimba serta mempelajari pengaruh tingkat konsentrasi fraksi ekstrak daun mengkudu dan fraksi ekstrak daun mimba dalam menekan pertumbuhan dan sporulasi jamur $C$. capsici secara in vitro. Penelitian ini dilakukan di Laboratorium Ilmu Penyakit Tumbuhan Fakultas Pertanian Universitas Lampung pada bulan April 2015 sampai Juli 2015. Alat yang digunakan antara lain alat fraksinasi sederhana, mikropipet, haemocytometer, dan Laminar air flow. Bahan yang digunakan antara lain daun mengkudu, daun mimba, biakan C. capsici, dan media Potato Sucrose Agar (PSA). Penelitian ini menggunakan rancangan acak lengkap (RAL) tersarang dengan dua faktor dan data dianalisis ragam kemudian dilanjutkan dengan perbandingan polinomial ortogonal pada taraf $1 \%$. Hasil penelitian menunjukkan bahwa fraksi ekstrak daun mengkudu dan fraksi ekstrak daun mimba memiliki keefektifan yang tidak berbeda dalam menghambat pertumbuhan dan sporulasi $C$. capsici secara in vitro. Tingkat konsentrasi kedua jenis fraksi ekstrak tanaman tersebut berbeda dalam menghambat pertumbuhan dan sporulasi $C$. capsici. Semakin tinggi tingkat konsentrasi fraksi ekstrak tanaman uji tidak selalu diikuti dengan meningkatnya daya hambat terhadap pertumbuhan diameter koloni $C$. capsici, tetapi semakin tinggi tingkat konsentrasi fraksi ekstrak tanaman tersebut semakin efektif untuk menghambat sporulasi $C$. capsici.
\end{abstract}

Kata kunci: Colletotrichum capsici, fraksi ekstrak daun mengkudu, fraksi ekstrak daun mimba.

\section{PENDAHULUAN}

Budidaya tanaman cabai besar seringkali mengalami kendala terutama dalam meningkatkan produksi. Salah satu kendala peningkatan produksi cabai besar adalah faktor lingkungan yang tidak menentu dan serangan hama penyakit tanaman. Penyakit utama yang sering menyerang tanaman cabai besar adalah antraknosa. Rostini (2012) menyatakan bahwa penyakit antraknosa (patek) dapat disebabkan oleh patogen Colletotrichum capsici, C. acutatum, dan $C$. gloeosporioides. Penyakit antraknosa dapat menyebabkan gagal panen hingga 20-90\% terutama pada musim hujan (Alex, 2011). Oleh karena itu, perlu dilakukan pengendalian penyakit antraknosa.

Teknik pengendalian yang sering digunakan oleh petani untuk mengendalikan penyakit antraknosa adalah penggunaan fungisida sintetik. Residu bahan aktif dari fungisida sintetik dapat bertahan lama pada buah cabai pascapanen sehingga membahayakan manusia jika mengkonsumsinya. Alternatif pengendalian yang dapat dilakukan adalah penggunaan fungisida nabati. Sudarmo
(2009) menyatakan penggunaan fungisida nabati dapat mengurangi pencemaran lingkungan dan harganya relatif murah dibandingkan menggunakan fungisida sintetik.

Tanaman mengkudu dan mimba merupakan tanaman yang dapat digunakan sebagai fungisida nabati. Tanaman mengkudu mengandung berbagai senyawa bioaktif diantaranya minyak atsiri, saponin, triterpenoid, fenol, tanin, dan glikosida (Djauhariya dan Rosman, 2006 ; Aryadi, 2014). Rani dkk. (2013) menyatakan senyawa yang terkandung didalam ekstrak daun mengkudu efektif menghambat pertumbuhan diameter koloni $C$. capsici. Syarmalina dan Dian (2005) melaporkan bahwa tanaman mimba berpotensi sebagai antimikroba karena mengandung senyawa azadirachtin, paraisin, alkaloid, dan komponen minyak atsiri yang mengandung senyawa sulfida.

Efri dan Aeny (2014) melaporkan bahwa 1000 ppm ekstrak daun mengkudu dan ekstrak daun mimba yang terlarut dalam air dapat menghambat pertumbuhan diameter koloni dan sporulasi jamur C. capsici. Berdasarkan hal tersebut, perlu dilakukan pengujian lanjutan terhadap tingkat konsentrasi kedua jenis ekstrak 
tanaman tersebut agar didapatkan keefektifan yang berbeda dan pemberian konsentrasi tinggi akan menunjukkan keefektifan optimum dalam menekan pertumbuhan dan perkembangan jamur $C$. capsici secara in vitro. Maka dalam penelitian ini akan diuji beberapa konsentrasi di bawah dan di atas $1000 \mathrm{ppm}$ $(0,10 \mathrm{~g} / 100 \mathrm{ml}$ media). Oleh karena itu penelitian ini bertujuan untuk mengetahui tingkat keefektifan fraksi ekstrak daun mengkudu dan fraksi ekstrak daun mimba serta mempelajari pengaruh tingkat konsentrasi fraksi ekstrak daun mengkudu dan fraksi ekstrak daun mimba dalam menekan pertumbuhan dan sporulasi jamur $C$. capsici secara in vitro.

\section{BAHAN DAN METODE}

Penelitian ini dilaksanakan pada bulan April 2015 sampai dengan Juli 2015, bertempat di Laboratorium Penyakit Fakultas Pertanian Universitas Lampung. Bahan-bahan yang digunakan yaitu daun mengkudu, daun mimba, biakan C. capsici, dan media Potato Sucrose Agar (PSA). Alat yang digunakan yaitu alat fraksinasi sederhana, alumunium foil, autoklaf, cawan petri, labu erlenmeyer, haemocytometer, mikroskop majemuk, mikropipet, Laminar air flow, kaca preparat, bunsen, dan bor gabus.

Perlakuan dalam percobaan ini disusun dalam rancangan acak lengkap (RAL) tersarang dengan dua faktor. Faktor pertama adalah jenis ekstrak tanaman yaitu fraksi ekstrak daun mengkudu $\left(\mathrm{R}_{1}\right)$ dan fraksi ekstrak daun mimba $\left(\mathrm{R}_{2}\right)$. Faktor kedua tingkat konsentrasi jenis ekstrak tanaman yang digunakan $(\mathrm{F})$ terdiri dari: $0 \mathrm{ppm}(0,00 \mathrm{~g} / 100 \mathrm{ml} / \mathrm{media})\left(\mathrm{F}_{0}\right), 500 \mathrm{ppm}$ $(0,05 \mathrm{~g} / 100 \mathrm{ml} / \mathrm{media})\left(\mathrm{F}_{1}\right), 1000 \mathrm{ppm}(0,10 \mathrm{~g} / 100 \mathrm{ml} /$ media) $\left(\mathrm{F}_{2}\right), 1500 \mathrm{ppm}(0,15 \mathrm{~g} / 100 \mathrm{ml} /$ media $)\left(\mathrm{F}_{3}\right)$, dan $2000 \mathrm{ppm}(0,20 \mathrm{~g} / 100 \mathrm{ml} /$ media $)\left(\mathrm{F}_{4}\right)$. Setiap perlakuan diulang sebanyak 5 kali sehingga diperoleh 50 satuan percobaan. Data hasil pengamatan dianalisis ragam dan perbedaan nilai tengah antar perlakuan diuji dengan perbandingan polinomial ortogonal pada taraf nyata $1 \%$.

Langkah-langkah dalam pelaksanaan penelitian yang pertama adalah pembuatan ekstrak daun mengkudu (Morinda citrifolia L.) dan ekstrak daun mimba (Azadirachta indica A. Juss.). Daun yang digunakan untuk pembuatan ekstrak daun mengkudu dan daun mimba adalah daun yang segar. Daun mengkudu yang digunakan sebanyak $200 \mathrm{~g}$ dicuci dengan air bersih. Daun dipotong-potong dan diblender sampai halus dengan air $1000 \mathrm{ml}$ kemudian dimasukkan ke dalam alat fraksinasi. Proses fraksinasi yang dilakukan untuk daun mengkudu menggunakan pelarut air, hasil ekstraksi ditampung dalam nampan. Ekstrak dari daun mengkudu dikeringanginkan selama 14 -16 hari kemudian dikeruk, dimasukkan ke dalam cawan petri, dan ditimbang untuk disimpan sebelum menyiapkan media uji. Proses fraksinasi ekstrak daun mimba dilakukan dengan cara yang sama seperti pembuatan fraksi ekstrak daun mengkudu.

Pembuatan Media Uji. Media PSA yang telah steril dibagi ke dalam 10 labu erlenmeyer berukuran 100 ml. Masing-masing fraksi ekstrak tanaman uji dicampurkan dalam media PSA dengan konsentrasi 0 ppm (kontrol), 500 ppm ( 0,05 g ekstrak tanaman uji $/ 100$ $\mathrm{ml}$ media), $1000 \mathrm{ppm}(0,1 \mathrm{~g}$ ekstrak tanaman uji $/ 100 \mathrm{ml}$ media), $1500 \mathrm{ppm}(0,15 \mathrm{~g}$ ekstrak tanaman uji $/ 100 \mathrm{ml}$ media), dan 2000 ppm (0,2 g ekstrak tanaman uji/100 $\mathrm{ml}$ media). Pencampuran dilakukan pada saat media masih panas (cair).

Langkah kedua adalah penyiapan isolat $C$. capsici. Jamur yang diduga $C$. capsici diisolasi dari buah cabai yang bergejala antraknosa. Isolasi dilakukan dengan cara memotong jaringan kulit buah cabai antara yang bergejala dan tidak bergejala dengan ukuran $5 \mathrm{~mm}$. Selanjutnya potongan kulit buah cabai tersebut diinokulasi pada media PSA, diinkubasi dalam suhu ruang selama 3 hari, dan identifikasi untuk memastikan jamur yang tumbuh adalah $C$. capsici.

Langkah ketiga adalah uji penghambatan pertumbuhan $C$. capsici. Uji penghambatan pertumbuhan $C$. capsici yang digunakan dalam percobaan ini adalah teknik makanan beracun (Poisoned Food Technique). Pengujian dilakukan dengan menginokulasikan jamur C. capsici dalam media yang telah dicampur dengan ekstrak tanaman uji. Hasil inokulasi C. capsici pada media kemudian diinkubasikan pada suhu kamar selama 15 hari.

Langkah selanjutnya adalah pengamatan. Data pertumbuhan koloni jamur yang didapat merupakan ratarata empat kali pengukuran diameter pada daerah yang berbeda. Pengamatan ini dilakukan pada hari ke-2 hingga hari ke-15 setelah inokulasi. Perhitungan jumlah spora dilakukan sebanyak lima kali ulangan pada setiap perlakuan. Laju jumlah spora dihitung dalam lima sampel kotak sedang (pada hari ke-15 setelah inokulasi) dengan rumus (Syahnen dkk., 2014):

$$
\mathrm{S}=\mathrm{R} \times \mathrm{K} \times \mathrm{F}
$$

Keterangan:

$\mathrm{S}=$ jumlah spora

$\mathrm{R}=$ jumlah rata-rata spora pada 5 bidang pandang haemocytometer

$\mathrm{K}=$ konstanta koefisien alat $\left(0,25 \times 10^{6}\right)$

$\mathrm{F}=$ faktor pengenceran yang dilakukan 


\section{HASIL DAN PEMBAHASAN}

Pengaruh jenis ekstrak tanaman terhadap pertumbuhan diameter koloni dan kerapatan spora $C$. capsici secara in Vitro dapat dilihat pada Tabel 1. Pada Tabel 1 dapat dilihat bahwa hasil analisis ragam pengamatan hari ke-2 sampai dengan ke-15 pertumbuhan diameter koloni dan kerapatan spora $C$. capsicisecara in vitro. Jenis ekstrak tanaman tidak memberikan pengaruh yang berbeda nyata terhadap pertumbuhan diameter koloni dan kerapatan spora C.capsici.

Pada daun mengkudu terdapat senyawa aktif yaitu antrakuinon, alkaloid, saponin, flavonoid dan terpenoid (Kameswari dkk., 2013), minyak atsiri, triterpenoid, fenol, tanin, dan glikosida berfungsi sebagai antibakteri (Aryadi, 2014). Penelitian Ella dkk. (2013) menunjukkan bahwa minyak atsiri sereh dapur efektif menekan pertumbuhan jamur Aspergillus sp. Sedangkan pada daun mimba juga terdapat senyawa aktif flavonoid, saponin, dan tanin (Puspitasari dkk.,2009), alkaloid, terpenoid, steroid, tanin, antrakuinon, dan asam lemak (Handayani dkk., 2012).

Menurut Taofik dkk. (2010) senyawa flavonoid, alkaloid, dan tanin bersifat polar dari ekstrak daun paitan dengan pelarut air. Martsolich (2007) juga menyebutkan hasil uji fitokimia ekstrak daun jati belanda dengan pelarut air mengandung flavonoid, saponin, tanin, dan fenolik hidrokuinon. Selaras dengan hasil penelitian
Wafa (2011) tentang identifikasi fraksi air daun gambir menunjukkan bahwa senyawa flavonoid yang terkandung di dalam daun gambir lebih banyak terlarut di dalam air. Siahaan (2012) menyatakan bahwa ekstrak urang aring yang mengandung senyawa flavonoid, alkaloid, tanin, dan saponin mampu menghambat pertumbuhan jamur $F$. oxysporum $f$. lycopersici. Dengan demikian diduga dalam penelitian ini senyawa yang terlarut dalam fraksi ekstrak daun mengkudu dan ekstrak daun mimba yang diekstrak dengan pelarut air adalah senyawa flavonoid, alkaloid, saponin dan tanin. Sehingga fraksi ekstrak daun mengkudu dan ekstrak daun mimba mempunyai kemampuan yang tidak berbeda nyata dalam menekan pertumbuhan diameter koloni dan kerapatan spora $C$. capsici secara in vitro.

Pengaruh Konsentrasi Fraksi Ekstrak Daun Mengkudu terhadap Pertumbuhan Diameter Koloni dan Kerapatan Spora C. capsici Secara in Vitro dapat dilihat pada Gambar 1. Berdasarkan uji polinomial ortogonal menunjukkan pengaruh taraf konsentrasi fraksi ekstrak daun mengkudu terhadap pertumbuhan diameter koloni jamur $C$. capsici, berpola kuadratik dengan persamaan $\mathrm{Y}=265,1 \mathrm{x}^{2}-48,64 \mathrm{x}+8,033\left(\mathrm{R}^{2}=0,445\right)$ (Gambar 1). Pada Gambar 1 dapat dilihat bahwa, pada awalnya pengaruh konsentrasi fraksi ekstrak daun mengkudu konsentrasi 0,00 sampai $0,1(\mathrm{~g} / 100 \mathrm{ml}$ media) menunjukkan pengaruh yang kuat tetapi selanjutnya pengaruh yang diberikan semakin melemah seiring peningkatan konsentrasi. Dari hasil penelitian tersebut

Tabel 1. Pengaruh jenis ekstrak tanaman uji terhadap rata-rata pertumbuhan diameter koloni dan rata-rata kerapatan spora $C$. capsici secara in vitro.

\begin{tabular}{cccc}
\hline Waktu pengamatan & \multicolumn{2}{c}{ Rata-rata diameter koloni (cm) } & F-Hitung \\
\cline { 2 - 3 } & $\begin{array}{c}\text { Ekstrak daun } \\
\text { mengkudu }\end{array}$ & $\begin{array}{c}\text { Ekstrak daun } \\
\text { mimba }\end{array}$ & \\
\hline 2 hsi & 0,90 & 1,04 & $0,882^{\text {tn }}$ \\
3 hsi & 1,30 & 1,63 & $1,279^{\text {nn }}$ \\
4 hsi & 1,70 & 2,13 & $1,221^{\text {tn }}$ \\
5 hsi & 2,21 & 2,70 & $0,618^{\text {tn }}$ \\
6 hsi & 2,72 & 3,35 & $1,101^{\text {tn }}$ \\
7 hsi & 3,19 & 3,93 & $1,200^{\text {tn }}$ \\
8 hsi & 3,87 & 4,72 & $1,164^{\text {tn }}$ \\
9 hsi & 4,38 & 5,28 & $1,102^{\text {nn }}$ \\
10 hsi & 4,94 & 5,93 & $1,230^{\text {tn }}$ \\
11 hsi & 5,49 & 6,45 & $1,010^{\text {tn }}$ \\
12 hsi & 5,94 & 6,80 & $1,064^{\text {tn }}$ \\
13 hsi & 6,41 & 7,36 & $0,979^{\text {tn }}$ \\
14 hsi & 6,78 & 7,72 & $0,935^{\text {tn }}$ \\
15 hsi & 7,146 & 8,11 & $1,056^{\text {tn }}$ \\
\hline Kerapatan Spora ke- 15 hsi (spora/ml) & $0,92 \times 10^{7}$ & $0,97 \times 10^{7}$ & $0,010^{\text {tn }}$ \\
\hline
\end{tabular}

Keterangan: $\mathrm{tn}=$ tidak nyata pada taraf $1 \%$ dan $5 \%$; hsi $=$ hari setelah inokulasi. 
terlihat bahwa semakin tinggi konsentrasi yang diberikan tidak selalu diikuti dengan penghambatan pertumbuhan diameter koloni jamur $C$. capsici.

Hal yang sama dilaporkan oleh Suharjo dan Aeny (2011) yang menyatakan bahwa tingkat konsentrasi $40 \%$ ekstrak kasar gulma siam lebih baik dibandingkan dengan konsentrasi $10 \%, 20 \%, 30 \%$, dan 50\% untuk menghambat pertumbuhan diameter koloni jamur Phytophthora palmivora secara in vitro. Diduga efektivitas ekstrak tanaman dalam menghambat pertumbuhan diameter koloni jamur yang efektif tidak selalu dari taraf konsentrasi yang semakin tinggi. Hal ini selaras dengan hasil penelitian Suharjo dan Aeny (2011) yang menyatakan bahwa ekstrak kasar gulma siam mempunyai batas taraf konsentrasi optimum dalam menekan pertumbuhan Phytophthora palmivora. Hasil ini menguatkan dugaan bahwa fraksi ekstrak daun mengkudu memiliki batas taraf konsentrasi dalam menghambat pertumbuhan diameter koloni jamur C.capsici secara in vitro.

Dari persamaan $\mathrm{Y}=265,1 \mathrm{x}^{2}-48,64 \mathrm{x}+8,033$ didapatkan nilai minimum untuk diameter koloni jamur C. capsici pada konsentrasi fraksi ekstrak daun mengkudu adalah $0,09 \mathrm{~g} / 100 \mathrm{ml}$ media dengan pertumbuhan diameter koloni adalah $5,8 \mathrm{~cm}$. Nilai minimum tersebut menggambarkan bahwa konsentrasi maksimum fraksi ekstrak daun mengkudu adalah 0,09 $\mathrm{g} / 100 \mathrm{ml}$ media.

Berdasarkan uji lanjut polinomial ortogonal menunjukkan adanya hubungan linier antara taraf konsentrasi fraksi ekstrak tanaman dengan kerapatan

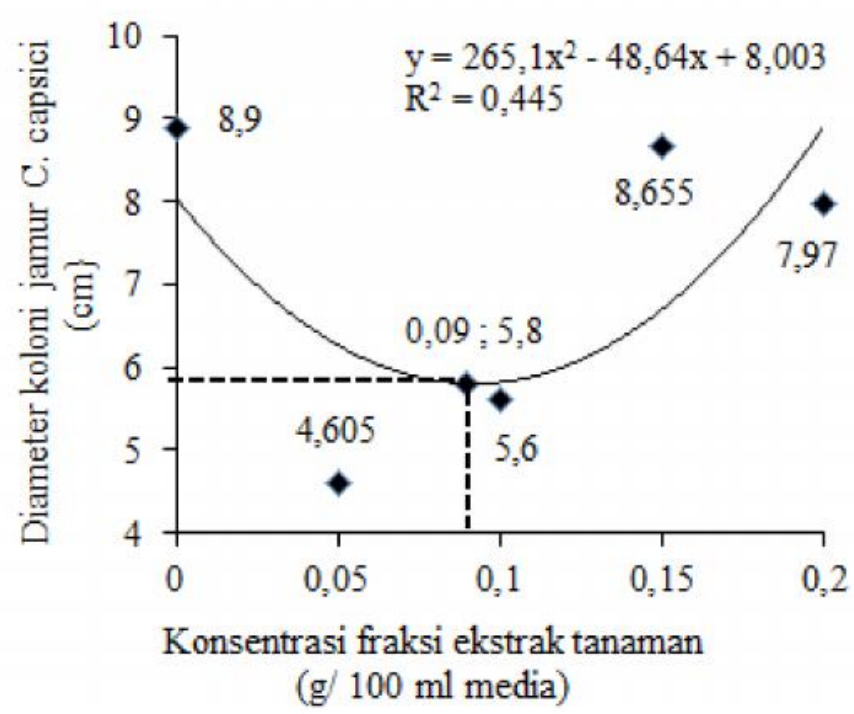

Gambar 1. Grafik pengaruh konsentrasi fraksi ekstrak daun mengkudu terhadap pertumbuhan diameter koloni jamur $C$. capsici secara in vitro pada 15 hsi. spora dengan persamaan linier $\mathrm{Y}=-7,544 \mathrm{x}+1,630\left(\mathrm{R}^{2}=\right.$ 0,602) (Gambar 2). Pada Gambar 2 dapat dilihat bahwa semakin tinggi taraf konsentrasi ekstrak mengkudu, semakin sedikit jumlah spora $C$. capsici yang dihasilkan. Pada penelitian ini pengaruh fraksi ekstrak daun mengkudu terhadap sporulasi lebih konsisten dibandingkan dengan pengaruhnya terhadap pertumbuhan diameter koloni jamur $C$. capsici secara in vitro.

Pengaruh Konsentrasi Fraksi Ekstrak Daun Mimba terhadap Pertumbuhan Diameter Koloni dan Kerapatan Spora C. capsici Secara in Vitro dapat dilihat pada Gambar 3. Hasil uji polinomial ortogonal menunjukkan bahwa pengaruh taraf konsentrasi fraksi ekstrak daun mimba terhadap pertumbuhan diameter koloni jamur $C$. capsici, berpola kuadratik dengan persamaan $Y=84 x^{2}-15,78 x+8,426\left(R^{2}=0,243\right)($ Gambar $3)$.

Pada Gambar 3 terlihat bahwa pengaruh taraf konsentrasi 0,00 sampai $0,1(\mathrm{~g} / 100 \mathrm{ml}$ media) semakin kuat tetapi selanjutnya pengaruh yang diberikan semakin melemah seiring peningkatan konsentrasi. Dari persamaan $Y=84 x^{2}-15,78 x+8,426$ didapatkan nilai minimum untuk diameter koloni jamur pada konsentrasi fraksi ekstrak daun mimba adalah $0,09 \mathrm{~g} / 100 \mathrm{ml}$ media dengan pertumbuhan diameter koloni jamur $C$. capsici adalah $7,68 \mathrm{~cm}$. Nilai minimum tersebut menggambarkan bahwa konsentrasi maksimum fraksi ekstrak daun mimba adalah $0,09 \mathrm{~g} / 100 \mathrm{ml}$ media.

Berdasarkan uji polinomial ortogonal menunjukkan adanya hubungan linier antara taraf konsentrasi fraksi

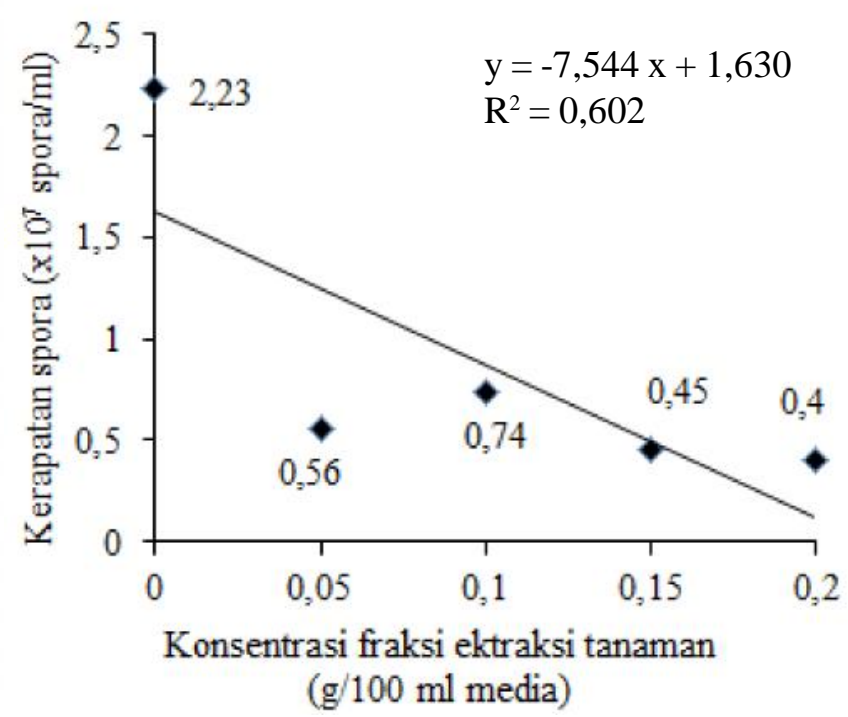

Gambar 2. Grafik pengaruh fraksi ekstrak daun mengkudu terhadap jumlah spora per $\mathrm{ml} C$. capsici pada 15 hsi. 


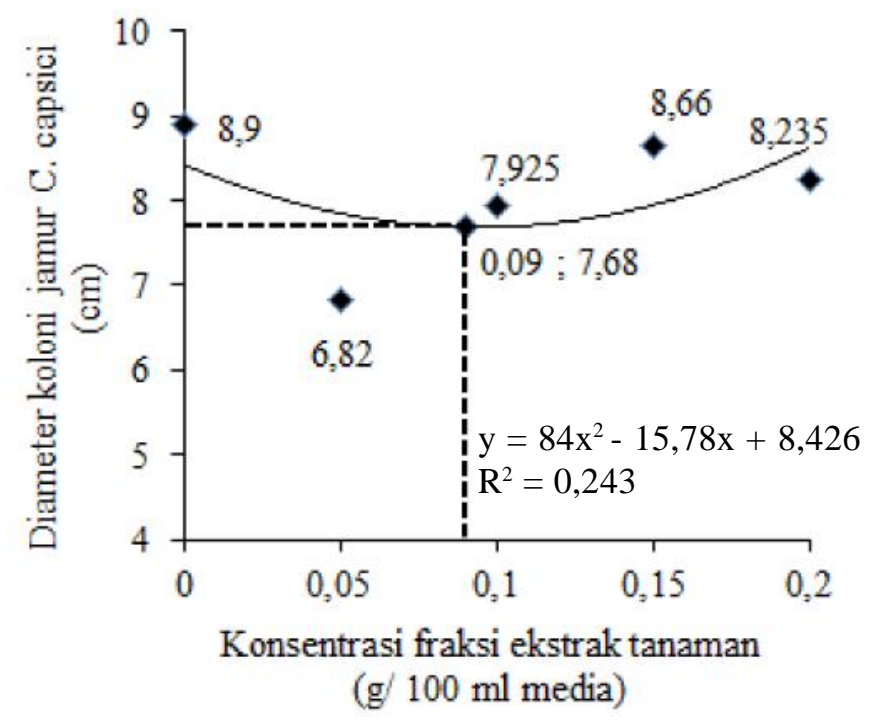

Gambar 3. Grafik pengaruh konsentrasi fraksi ekstrak daun mimba terhadap pertumbuhan diameter koloni jamur $C$. capsici secara in vitro pada 15 hsi

ekstrak daun mimba dengan kerapatan spora dengan persamaan linier $\mathrm{Y}=-7,28+1,654\left(\mathrm{R}^{2}=0,611\right)(\mathrm{Gambar}$ 4). Pengaruh taraf konsentrasi ekstrak daun mimba terhadap jumlah spora semakin kuat seiring dengan penambahan konsentrasi. Pada Gambar 4 dapat dilihat bahwa semakin tinggi konsentrasi ekstrak daun mimba semakin sedikit jumlah spora C. capsici yang dihasilkan. Pengaruh ekstrak daun mimba menunjukkan hasil yang konsisten seiring dengan peningkatan taraf konsentrasi dibandingkan dengan pengaruh yang diberikan terhadap pertumbuhan diameter koloni jamur $C$. capsici secara in vitro. Sehingga masing- masing taraf konsentrasi fraksi ekstrak daun mimba mempunyai kemampuan dalam menghambat jumlah spora $C$. capsici pada 15 hari setelah inokulasi.

\section{KESIMPULAN}

Dari hasil penelitian yang telah dilakukan dapat disimpulkan bahwa fraksi ekstrak daun mengkudu dan fraksi ekstrak daun mimba memiliki keefektifan yang tidak berbeda dalam menghambat pertumbuhan dan sporulasi C. capsici secara in vitro. Tingkat konsentrasi fraksi ekstrak tanaman uji memiliki pengaruh yang berbeda dalam menghambat pertumbuhan dan sporulasi C. capsici secara in vitro. Semakin tinggi taraf konsentrasi fraksi ekstrak tanaman uji tidak selalu diikuti dengan penghambatan pertumbuhan diameter koloni jamur $C$. capsici, tetapi semakin efektif untuk menghambat sporulasi $C$. capsici secara in vitro.

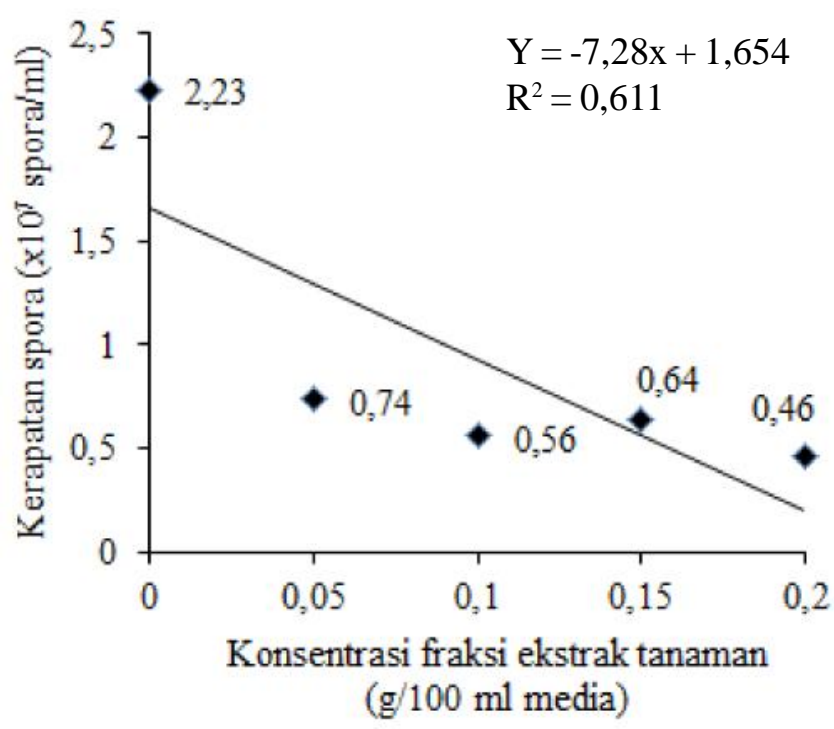

Gambar 4. Grafik pengaruh fraksi ekstrak daun mimba terhadap jumlah spora per $\mathrm{ml}$ C. capsici pada 15 hsi.

\section{DAFTAR PUSTAKA}

Alex. 2011. Usaha Tani Cabai: Kiat Jitu Bertanam Cabai di Segala Musim. Pustaka Baru Press. Yogyakarta. $160 \mathrm{hlm}$.

Aryadi, I.G.A.I.P. 2014. Pengaruh ekstrak daun mengkudu (Morinda citrifolia L.) terhadap pertumbuhan Staphylococcus aureus sebagai penyebab abses periodontal secara in vitro. Skripsi. Universitas Mahasaraswati Denpasar. Denpasar. $64 \mathrm{hlm}$.

Djauhariya, E. dan Rosman R. 2006. Status Perkembangan Teknologi Tanaman Mengkudu. Tersedia: http://balittro.litbang.pertanian.go.id/ind/ images/file/perkembangan\%20TRO/edsus19n01/ 2mengkudu.pdf, [5 April 2015].

Efri dan T.N. Aeny. 2014. Skrining dan aplikasi fraksi ekstrak tumbuhan sebagai biofungisida ramah lingkungan untuk mengendalikan penyakit antraknosa Colletotrichum capsici pada tanaman cabai. Laporan Penelitian Hibah Bersaing. Universitas Lampung. Bandar Lampung. $30 \mathrm{hlm}$.

Ella, M.U., K. Sumiartha, N.W. Suniti, I.P. Sudiarta, dan N.S. Antara. 2013. Uji efektivitas konsentrasi minyak atsiri sereh dapur (Cymbopogon citratus (DC.) Stapf) terhadap pertumbuhan jamur Aspergillus sp. secara in vitro. Jurnal Agroteknologi Tropika 2(1) : 39-48. 
Handayani, N., M.W. Wartono, dan K. M. Riskha. 2012. Identifikasi dan uji aktivitas antibakteri fraksi teraktif daun mimba (Azadirachta indica A. Juss). Alchemy Jurnal Penelitian Kimia. 8(1): 57-69.

Kameswari, M. S., I. N. K. Besung, dan H. Mahatmi. 2013. Perasan daun mengkudu (Morinda citrifolia) menghambat pertumbuhan bakteri Escherichia coli secara in vitro. Jurnal Indonesia Medicus Veterinus. 2(3): 322-330.

Martsolich, K.A. (2007). Potensi antioksidasi ekstrak air dan ekstrak etanol 70\% daun jati belanda (Guazuma ulmifolia Lamk.). Skripsi. Fakultas Matematika dan Ilmu Pengetahuan Alam. Institut Pertanian Bogor. Bogor. $31 \mathrm{hlm}$.

Puspitasari, A., Sudarso, dan B.A. Dhiani 2009. Aktivitas antijamur ekstrak etanol soxhletasi dan maserasi daun mimba (Azadirachta indica) terhadap Candida albicans. Pharmacy. 6(2): 6-13.

Rani, S. E., Efri, dan J. Prasetyo. 2013. Pengaruh berbagai tingkat fraksi ekstrak daun mengkudu (Morinda citrifolia L.) terhadap pertumbuhan Colletotrichum capsici penyebab penyakit antraknosa pada cabai (Capsicum annuum L.) secara in vitro. Jurnal Agrotek Tropika. 1(1) : 92-97.

Rostini, N. 2012. 9 Strategi Bertanam Cabai Bebas Hama dan Penyakit. PT. Agromedia Pustaka. Jakarta. $98 \mathrm{hlm}$.

Siahaan, P. 2012. Pengaruh ekstrak urang aring (Eclipta albaL. Hask.) terhadap pertumbuhan jamur
Fusarium oxysporum f. lycopersici (Sacc.) Snyder \& Hans. Jurnal Bioslogos. 2(1): 28-36.

Sudarmo, S. 2009. Pestisida Nabati, Pembuatan dan Pemanfaatannya. Kanisius. Yogyakarta. 161 hlm.

Suharjo, R. dan T.N. Aeny. 2011. Eksplorasi potensi gulma siam (Chromolaena odorata) sebagai biofungisida pengendali Phytophthora palmivora yang diisolasi dari buah kakao. Jurnal HPT Tropika. 11(2) : 201-209.

Syarmalina dan R. L. Dian. 2005. Uji efek antibakteri ekstrak daun mimba (Azadirachta indica A. Juss.) terhadap bakteri. Prosiding Seminar Nasional Tumbuhan Obat Indonesia XXVII. Bogor, 15-16 September 2005. Hlm 274-276.

Syahnen, D.N.S. Desianty, E. Sry, dan Pinem. 2014. Teknik uji mutu agens pengendalian hayati (APH) di Laboratorium. Tersedia: http://ditjenbun. pertanian.go.id/bbpptpmedan/berita-279-teknikuji-mutu-agens-pengendalian-hayati-aph-dilaboratorium.html, [14 Mei 2015].

Taofik, M., E. Yulianti, A. Barizi, dan E.K. Hayati. 2010. Isolasi dan identifikasi senyawa aktif ekstrak daun paitan (Thitonia diversifolia) sebagai bahan insektisida botani untuk pengendalian hama tungau eriophyidae. Alchemy Jurnal. 2(1) : 104-157.

Wafa, N. I. 2011. Uji aktivitas antibakteri fraksi air daun gambir (Uncaria gambir Roxb.) dengan mikrodilusi dan analisis komponen penyusunnya. Skripsi. Fakultas Matematika dan Ilmu Pengetahuan Alam. Institut Pertanian Bogor. Bogor. $32 \mathrm{hlm}$. 